\title{
Social Interactions among Students at Addis Hiwot Coffee House, Tewodros Campus, University of Gondar
}

\author{
Esubalew Aman Mezmir \\ Lecturer at Wolkite University, Department of Sociology
}

\begin{abstract}
This study investigates student-student interactions at coffee house situated in University of Gondar Tewodros campus. To this end, the study was conducted on interaction among students at Addis Hiwot coffee house to explore form and types of student-student interactions, to investigates how drinking coffee is related to students' motivation, sleep, mood and academic performance, and to identify the effects of their interactions. A qualitative research approach was employed to collect and analyze the data needed to address the aforementioned objectives. Accordingly, non-participant observation method was used to investigate student-student interactions in the coffee house to better understand and capture the context within which students interact. To this effect, all social interactions of students at the coffee house were critically observed for an hour and a half with an average of 30 minutes during 3 phases across 3 days and the observation dates were lasted from October 23 to October 25, 2019. The study shows that the form and types of student-student interaction in the study area is different across gender for instance. In addition, the study reveals that the form and types of social interaction among students are different based on the number of students involved on the gatherings, the time when there is better wireless internet connection, and so on. The study further reveals that despite the fact that students take coffee as a gathering with their friends, students mostly drink coffee before attending the class for energizing and alert purpose.
\end{abstract}

Keywords: Observation, Students-Students Interaction, Coffee House, University of Gondar, Tewodros Campus. DOI: $10.7176 /$ RHSS/10-19-05

Publication date:October $31^{\text {st }} 2020$

\section{Introduction}

In Great Good Place, Ray Oldenburg (1999) emphasizes the importance of neighborhood gathering places in enhancing the lives of people. Oldenburg defines these gathering locations as third places, and further states that third places are not home nor work, but a place between home and work where people spend their time as a community. Oldenburg describes third places as a generic designation for a great variety of public places that host the regular, voluntary, informal, and happily anticipated gatherings of individuals beyond the realms of home and work (Oldenburg, 1999).

In addition to home and work, people needs informal social spaces, or third places, that provide an opportunity to connect with the people in communities and give a balance to the increased privatization of public life. The concept of "third place" is related to the concept of public, which is defined by Habermas as "the site of collective performance that brings together those who are different from one another precisely because they are different" (Habermas, 1956).

To this end, coffee houses can be labeled as "third places," or public spaces that accommodate the regular, voluntary, and informal gatherings of individuals beyond the realms of home and work. Since early the main function of the coffee houses remains the same, serving as a space for social engagement and networking. Addis Hiwot Coffee House is one of a space serving as a space for social interaction of students at university of Gondar, Tewodros campus.

Ever since I joined Gondar University, the goal of Addis Hiwot Coffee House has been to create warm, welcoming, and timelessly beautiful spaces where the students can gather and connect over incredible tasty coffee. That is really what makes Addis Hiwot Coffee House so special for the campus students to recreate, interact and discuss many issues.

This coffee house could be labeled as an important place to promote healthy student-student interactions and practice Ethiopian core culture because; it is a place where a ritual way of preparing and drinking coffee is available as a mark of hospitality. Along with this, this study aimed to examine student-student interactions at Addis Hiwot coffee house situated at University of Gondar, Tewodros campus. First, it examines the form and types of studentstudent interactions in the coffee house. Second, it closely investigates how drinking coffee is related to students' motivation, sleep, mood and academic performance. Third, it investigates why students meeting at coffee house are more interested to attach themselves on using Face book, discussing football, religious, politics and romantic issues than of talking about academic issues. Finally, it stresses the effects of their interactions.

\section{Objectives}

In phase 1 the researcher has visited Tewodros campus student-student interactions. The objectives here were to follow up when, how, where students usually interact and what are core of their interactions. 


\section{Significance of the Study}

The significance of the study is summarized as follows:

$>$ Using the recommended approach derived from the result of this observation, the campus will be able to implement appropriate policy to promote social interaction among students in the campus.

$>$ Helpful to show how student-student interactions determine academic learning environment both in the class room and out of class rooms.

$>$ For the researcher, the study will help him to discover critical areas of social and cultural interactions around the coffee house that many researchers yet unable to investigate.

\section{Site Description}

The study was fielded in a single coffee house, at University of Gondar Tewodros Campus. Nestled in front of Veterinary library, Addis Hiwot coffee house is a useful campus setting for a study of social interaction in University of Gondar Tewodros Campus. First, its relative green nature of the setting with contented seating chair make the place preferable for many of the campus students to be gathered together. Second, since there is free wireless internet service around the coffee house most of the campus students preferred to spent sometimes there. These relative advantages of the study setting have likely had implications for social interaction in general.

Within University of Gondar Tewodros Camus, the specific site of the study Addis Hiwot has two advantages. First, it can be considered broadly representative of students from different background. At the time of observation it had been noticed that students at the study site are from different ethnic backgrounds. Second, in terms of characteristics that might affect interactional patterns across gender was broadly representative.

Together, these two factors make the study site to conduct a reasonable comparison of student-student interactions on cultural and gender grounds.

\section{Method of the Study}

The study was conducted with the objective of exploring student-student interactions at Addis Hiwot coffee house situated at the University of Gondar Tewodros campus. To this effect, the study has employed non participant observation.

\section{Observation and Duration of Field Observation}

The study primarily relied on qualitative data generated by observation. I used non-participant observation method to investigate student-student interactions in the coffee house to better understand and capture the context within which students interact. I decided to view actions and interactions of students. In observing the interactions of students, I detached or distanced myself from them or without interacting with them. Study participants didn't know that they were being observed. I employed non-participant method because if I had observed student interactions with the knowledge of them, they would have changed their behavior of interactions.

All social interactions of students at Addis Hiwot coffee house situated at the University of Gondar Tewodros campus were critically observed for an hour and a half with an average of 30 minutes during 3 phases across 3 days in order to address central issues of the study. The observation dates were lasted from October 23 to October $25,2019$.

\section{Method of Data Analysis}

The study employed thematic analysis method, in which the data are analyzed on the basis of coding of observation notes; which includes details of field notes; analytic memos; recording of personal experiences, and context (Neuman, 2007). The analysis process started right after the first 30 minutes observation is completed. The researcher took detail observational notes during the observation sessions in Amharic, which were, in turn, translated into English without changing their original meanings. The study searched for and showed patterns in the recurrent behavior of students. Then, the researcher organized and interprets the data on the basis of different emerged themes in the field.

\section{Study Findings \\ Phase I: Time period October 23, 2019}

My first observation on October 23, 2019 took place for 30 minutes at Addis Hiwot Coffee House. Upon entering the coffee house I strategically positioned myself so that I could easily observe the other groups of student interactions. In my observation I localized my gaze to racially heterogeneous groups of students in particular. I watched four racially heterogeneous groups of students sitting differently based on the language they speak. I carefully observed which language they speak, issues they discuss and where they are seated within the coffee house, and the nature of their interaction. I listened intently for remnants of conversations and interpretive body language. I also timed how long each group dined, drunk, and interact together. Interactions within these groups varied from lively to social, secluded and private interactions. The areas in which these interactions took place 
were depicted through which language they speak, which religious groups they follow, where interact, when to meet in the coffee house.

On the first phase of my observation, I observed different groups of students interacting for different purposes. Some are completely seems bad boys; others are talking about politics, a few others are religious and still others are talking about football game. I have started by gangs of bad boy looking. The bad boy looking gangs' style of communications and interactions are quite different from other segments of the groups interacting in the coffee house. They usually tend to speak each other cruelly. When one of them sees a girl passing around he calls others and start giggling at her. Hence, most of the girls walking around and those who set to have coffee looks at the bad boy looking gangs with apprehension. Most of the bad boy looking guys is usually moving by lowering their trousers down to their waist; their hair style is somewhat different; life seems out of their control that they usually go depressingly; they often feel depressed because they feel stuck and hopeless of neglecting themselves.

Other students are talking about politics. They blame EPRDF government for current crisis in the country. The rest of them are discussing at the more lively interactions near the center of the coffee house where they discussed about the devotion of religion. That day while I was sitting in the coffee house, I saw female students who are followers of Orthodox Christianity coming from church and entering the coffee house. By default they seat next to my side and their proximity enabled me to observe what they were discussing. They discussed religious issues in which they belonged. They encourage each other not to be absent from church at least three days a week.

Other nature of interactions seemed to involve previous connections and common interest (for example there was a group of football players seated together and talking about football). They were talking about English football clubs: Arsenal, Manchester United, Chelsea, and Liverpool. They strongly discussed their strength, weakness of each clubs. They also discussed the personal strength and weakness of players from goal keepers to the attackers.

Other form of interaction is drinking tea and coffee which is believed as energizing drinks for studying is one of major factor for student-student interactions at the coffee house. In the first phase of my observation, I heard some students who had stimulant and energizing beliefs of drinking coffee before class and during stay in library. I heard when one of the students was asking the rest of students as follows: "Don't you feel boring if you go to library without drinking coffee? As she said, "I don't think it is advisable to go to library before drinking coffee because I feel depression, yawning and doze if I do not drink coffee before going library". Therefore, I have observed that a student mostly drink coffee before attending the class for energizing and alert purpose. So, what I observed is that people communicate, learn, and react based on symbolic communications.

On the first phase, I also held the question that "does students make interpersonal communications and interaction with each other or with social media?" I observed that majority of students were closely tied on reading Face book news feeds than talking to each other. As one order in the coffee house whatever he/she needs and began to consume, most of them usually pay attention to watching face book news feeds while they are taking coffee. This shows that the rise of social media has also contributed to student taking much of their time on social media instead of interacting with their peers.

\section{Phase II: Time period October 24, 2019}

In the second phase of my observation which took place for 30 minutes, I went to the field to differentiate which sexes are more interactive. My second observation was very exciting and yielded much information with regard to student interactions based on sex. In most of my observation in this day, students largely speak about love rather than academic issues.

In the same day, I held the questions "Do students interact with similar sex or they interact most with opposite sex?" in the coffee house. Notably, I observed that unchallenged is the notion that students yearn for more intimacy with their opposite than similar sexes. This doesn't mean that social distance between male to male or female to female interactions in the coffee house is almost exclusive one. There is also social interaction between male and male, and female and female.

During my observation I tried to distinguish the interactions between same and opposite sexes. From the observation, even if I observe students interacting with same sex, talks and discourses, student of opposite sex undertake often interaction around the coffee house. Along with this, I observed female student who was busy reading Face book news feed from their mobile phone in the coffee house. While interacting, I observed a number of opposite sex hugs in the coffee house that includes friendly hugs, simple love hugs to naughty hugs.

Among the naughty hugs, on that day her guy comes from behind and puts his arms around her eyes with sign of love. In this instance, he was covering her eyes from behind, protecting her eyes making her feel unseen. He immediately withdrew his hand from her eyes. As he lifted his hands, viewing him he was her friends, she immediately jumped from her seat and hugged him, saying, "Where have you been, my love".

Other form of hug is shaking hand and simple hug. This hug is the most common and frequently shared hug in the coffee house which is a simple handshake. When in doubt about the appropriateness of hugging another person, students simply extend their hand for a handshake particularly if they do not know well each other. 


\section{Women Hugging Women}

In the coffee house Women hug other women to express friendship and warmth. It is quite common and acceptable for women to hug other women frequently and for long durations. The hug that takes place between women may also involve a kiss on the cheek.

\section{Male-Male Hugging}

In the coffee house male also hug other male to express friendship and warmth. It is quite common and acceptable for men to hug other male frequently and for long durations. The hug that takes place between male-male doesn't usually involve a kiss on the cheek

\section{Phase III: Time period October 25, 2019}

On the third and last phase occurred on the $25^{\text {th }}$ of October, 2019, I intended to examine other types of interactions that University students desire to have with their opposite sex in the coffee house: academic, religious and love? Although students generally do not appear to be interested in closer, academically oriented relationships with other students, many students desire and expect more lovely oriented social relationships with their opposite sex. Contemporary male-male or female-female interactions at coffee house seem less formal than female-male interactions.

\section{Evaluation of the Observation Experience}

This was my first formal research observation experience. I had lots of experiences which served as challenges during this one hour and a half observation. In this research observational experience, I noticed the existence of plenty of social settings in our surroundings by which social interactions could happen in different forms. While observing at Addis Hiwot coffee house I immediately positions myself to an ideal location, which can help me to capture everything happening. At the outset of the observation I sat in a location that allowed me to see the entryway, experience a high trafficked area, and have table access to write my field notes. However, for all the benefits of this first day observation, there were many drawbacks: I could not see the back of the store since there was an obstruction of my sight and I could not hear personal conversations.

Overall, I think observation work is necessary in the field of research. Personally, I feel disclosure is prudent; however, I do understand the opposite side of the coin: an advantage of observation can be that the subject is unaware that he/she is being observed, allowing for behavior to be observed naturally. This is especially accurate for gathering particular data on people's habits.

\section{Implications for Future Observations}

If I were to observe again in this setting (student student interaction at Addis Hiwot coffee house) I would choose to move in the field at different times for observation in order to better capture human interactions and dialogue. Coming up with rich human interaction might provide important insight to understand participants' cultural beliefs, values, and norms based on the words and expressions they used.

This assignment helped me understand the strengths and the limitations of using observation as a research tool insofar as there were times that I felt I was able to see and hear desirable interactions; however, many other times I was overwhelmed by the sheer amount of action and movement. I did not know what I should be typing for my reflective field notes because I did not frame my question.

Taking pictures as artifacts helped me paint a broader perspective of my observation. I would use photographs in future observations since photographs strengthen written or language observations and thoughts. Sometimes I was more focused on the process of taking reflective field notes (asking myself what is important) than on what was transpiring in front of my own eyes. I think this is to be expected of a novice researcher.

\section{Conclusion}

The ultimate goal of this study was to observe student-student interaction at Addis Hiwot coffee house situated in University of Gondar, Tewodros campus. To this end, non-participant observation method was used to investigate student-student interactions in the coffee house to better able to understand and capture the context within which students interact. To this effect, all social interactions of students at the coffee house were critically observed for an hour and a half with an average of 30 minutes during 3 phases across 3 days and the observation dates were lasted from October 23-October 25, 2019.

Lippard (1997) said, "The search for someplace is the mythical search for the axis mundi, for a center, for space to stand, for something to hang on to." This quote emphasizes the importance of place and the value of place in the lives of people. The coffee house represented in this study provided different things to students at University of Gondar. Students were attached to this particular coffee house for a variety of reasons, with each being unique to the person and reflecting his or her lived experiences, current life situation, and motivation for visiting the place. Accordingly, the study shows that most of students motivation to attach themselves in the coffee house includes; 
desire to have romantic time with their mates, to have fun times with friends, and to be energetic and stimulated for class and study. Moreover, the form and types of student-student interaction in the coffee house is different across gender for instance. In addition, the study reveals that the form and types of social interaction among students are different based on the number of students involved on the gatherings, the time when there is better wireless internet connection, and so on.

\section{Reference}

Habermas J. 1956. The Structural Transformation of the Public Sphere: an Inquiry into a Category of Bourgeois Society. Cambridge, MA: MIT Press.

Lippard, L. (1997). The lure of the local: Sense of place in a multicentered society. New York: The New Press. Neuman, Lawrence. 2007. The Basics of Social Research (2nd edition). Boston: Pearson Education.

Oldenburg, R. (1999). The Great Good Place. New York: Marlowe \& Company. 